\section{TECHNOLOGY OF} BROACHING - RESEARCH OF
THE ROUGHNESS AND
MACHINE CAPABILITY

JOZEF MARTINOVIC, JOZEF PETERKA

Slovak University of Technology in Bratislava, Faculty of Materials Science and Technology in Trnava, Institute of Production Technologies, Trnava, Slovakia

DOI: 10.17973/MMSJ.2021_12_2021187

e-mail to corresponding autor : jozef.peterka@stuba.sk

The work deals with the technology of metal machining with a focus on the technology of broaching the internal shaped surfaces. The design of the drawing tools is a tool with several cutting edges, whereby the final shape of the inner shaped surface is made for one rectilinear movement of the tool. The cost of broaching tools is higher. For these reasons, the broaching technology is suitable for series production.

One part of the paper covers the research of the achieved roughness of the internal grooves when changing the cutting environment, an emulsion was used instead of oil. The second part involves the use of statistical methods in the technology of broaching internal contoured surfaces. The research is focused on the machine capability. The results of measuring the accuracy of the tolerated dimension of the inner holes after broaching are used as input values to this statistic.

broaching, roughness, capability, profile shape, accuracy

KEYWORDS

\section{INTRODUCTION}

Broaching machines perform a rectilinear movement. Broaching tools are used as tools - broaching mandrels. The shape, construction and material of the broaching tools guarantee high precision and quality of machining of parts by this technology of metal chip processing. The resulting force of broaching consists of the sum of the forces acting on all the engaging teeth [Vasilko 2012].

The workpiece is placed without clamping in a positioning jig mounted on the machine, where it is centered by a broaching tool during the rectilinear movement of the machine. The cutting speed in the broaching process is the speed at which the tool passes throgh the workpiece. The speed of the main movement is called the cutting speed and we call it $v_{c}$ [Lipa 2007]. After the end of the production of the broaching, the workpiece can, in view of further requirements, either have a final design of the inner shaped surface, or this shaped surface can be machined in further production operations. If these shaped surfaces are intended for further production operations, then they are usually operations of heat treatment of metals, or induction hardening in a given area of the inner shaped surface. The cutting tool is an active factor in the machining process. Provides chip formation of the machined surface [Vasilko 2007]. As the number of cutting teeth of the tool is larger, the tools for broaching the inner shaped surfaces are longer in size and have a rod-shaped shape. The design of the broaching tools [Karl 2021] represents a tool with several cutting edges [Wiemers 2021], where the required final shape of the inner shaped surface is produced for one rectilinear movement of the tool through the workpiece. This is a negative contour of the tooth shape of the broaching tool on the workpiece [DIN 2003]. Broaching tools are made mainly of highspeed steel, carbide materials are also used. The manufacturers also have the surface of broaching tools coated. The efficiency of the production process of metal chip processing by the technology of broaching of internal contoured surfaces is affected by the service life of broaching tools. Knowledge from tribology and tribotechnics is generally used in broaching processes [Petkova 2012].

The research of world authors in the field of broaching technology is devoted to the broaching machine, the broaching tools, the broaching control, the broaching process and cutting medium (environment):

In [Xu 2011] a testing system of broaching-load is designed. The testing system uses an industrial computer, a high-precision data-acquisition-card, two pressure-sensors, a displacementsensor and Borland $\mathrm{C}++$ to test the broaching-load on the base of broaching machine's electronic control system. The factual application in hydraulic broaching machine shows that the proposed system has a good performance on testing-accuracy. The proposed system gives an effective solution to broachingload testing.

In [Jing 2016] a surface textured broach was designed to slow the broach surface wear and increase the lifespan. Broaching $45 \#$ steel load test was carried out. The textured broach can reduce the tool wear due to the nice wear resistance of inverted triangle texture, significantly improves the cutting efficiency and broaching performance and increase lifespan.

In [Ozelkan 2011] Optimal design of broaching tools has a significant impact to increase the productivity and to obtain high quality products. In this paper, an optimisation model for broaching design is presented. The model results in a non-linear non-convex optimisation problem. Analysis of the model structure indicates that the model can be decomposed into smaller problems. The model is applied to a turbine disc broaching problem which is considered as one of the most complex broaching operations.

Various cutting environments have been investigated in [Navukkarasan 2020]. An attempt has been made to investigate, dry and cryogenic broaching of AISI 4340 steel, which is predominantly used in turbine and gear manufacturing industries. A cryogenic broaching setup was developed to conduct the experiment in pull-type broaching machining cycle. In cryogenic broaching an increase of micro-hardness by 4.26 $18.77 \%$, curtailment in cutting temperature by $46.85-65.12 \%$, and attrition in surface roughness by $87.94-96.35 \%$ is observed in correlation with dry broaching of AISI 4340 steel. TOPSIS analysis conducted for the experimental run evaluated, cutting speed of $2.1 \mathrm{~mm} / \mathrm{min}$ and depth of cut $8 \mathrm{~mm}$ as the close to ideal solution for dry and cryogenic broaching. In cryogenic broaching the surface morphology characteristics of the broached component are superior owing to the drop in temperature, curtailed lengths of the chips and colossal lubrication factor. This in turn causes, roughness value to drop by $54.11 \%$ in cryogenic broaching in correlation with dry broaching of AISI 4340 steel.

Authors [Makarov 2008] present the materials of broaching on various speeds of cutting are presented. Comparative research of influence the traditional broaching on low speeds of cutting $\left(v_{c}=2 \mathrm{~m} \cdot \mathrm{min}^{-1}\right)$ by the broaches from high speed steel R18 and the high-speed broaching $\left(v_{c}=26 \mathrm{~m} \cdot \mathrm{min}^{-1}\right)$ by the hard-alloy broaches VK8 on the change of intensity of wear of the 
broaches and formation of key parameters of quality of a superficial layer - a roughness and fatigue durability. Introduction of the high-speed broaching promotes the receipt of higher and stable parameters of quality of a superficial layer, increase of fatigue durability, reliability of gas-turbine engine parts and the minimal values of the tool wear intensity.

In [Makarov 2010] authors state, that theoretically and practically it is proved, that at the broaching there is an optimum condition of a zone of cutting at optimum temperature of cutting. At this temperature optimum conditions of formation of required parameters of quality of the processed surface and the minimal values of intensity of wear of the tool are observed. In the article the results of mathematical computer modeling for the decision of a problem of numerical calculation of temperature of cutting, thermal fields and optimum modes of cutting are submitted at broaching of hard machining alloys.

The technology of broaching of internal contoured surfaces of workpieces stands for the production of internal profile which is being shaped on the components with through-hole. In practice this through-hole $d$ is typically machined by turning or drilling as a preceding manufacturing operation. The resulting force of broaching consists of the sum of the forces acting on all the engaging teeth [Vasilko 2012]. The speed of the main movement is called the cutting speed and we call it $v_{c}$ [Lipa 2007] The linear motion of the broaching tool through the machined workpiece leads to the required shape of the internal section. It is a negative contour of the toothing of the broaching tool on the shaped component. In practice this shape is often in a form of a profile shape. It is suitable to use profile calibres and regulating gauges for the measurements of the section.

While indicating the effect of the process of broaching of the internal contoured surface on other parameters of the shaped component it is suitable to use the methods based on the statistical concept.

\section{MATERIALS AND METHODS}

This chapter presents a theoretical introduction to the physical causes of the roughness of the machined surface for the broaching technology and an overview of the statistical methods used to evaluate the broaching of the inner grooves.

\subsection{Theoretical analysis of roughness surface at broaching}

The technology of broaching the inner contoured surfaces is one of the technologies of metal chip processing. The cutting speeds used in broaching technology are relatively low and there are many contact friction surfaces between the broaching tool and the material to be machined. At present, we can talk about two directions of the emergence of new surfaces in production technologies. These are surfaces created by adding material (additive technologies) [Milde 2021] and removing material (machining). In our paper, we will focus on machining technology, where we again have two groups of technologies that create new surfaces in different ways, namely technologies:

- with defined cutting edge (turning, milling [Peterka 2020b, Vopat 2013], drilling [Kolesnyk 2020], boring [Sentyakov 2020], broaching etc.),

- with undefined cutting edge (grinding [Bradthat 2021, Peterka 2020a], honing, polishing, etc.).

In our paper, we will deal with the formation of a surface using broaching technology. From the point of view of machining theory, there are following physical causes of machined surfaces:

- copying the shape of the cutting edge to the workpiece,

- copying the roughness of the cutting edge itself into the workpiece,

- effect of vibration,

- effect of the increase.

For the analytical calculation of the roughness parameter of the machined surface, e.g. $R z$ there are many equations in many literary sources. If we consider the broaching technology and our specific case - circular broaching tool, for physical reasons, is involved in creating the surfase roughness:

- copying the roughness of the cutting edge itself into the workpiece,

- effect of increase (if any).

From this consideration we can write that:

$$
R z_{S U}=R z_{C E}
$$

where

$R z_{s U}$ - the maximum height of the machined surface profile $[\mu \mathrm{m}]$,

$R z_{C E}$ - the maximum height of the cutting edge surface profile $[\mu \mathrm{m}]$.

When broaching, we work at low cutting speeds (due to the cutting material used, the construction of the machines). At low cutting speeds, it is assumed that an increase will Built Up Edge (BUE). For these reasons, intensive lubrication is used in broaching technology, the purpose of which is to reduce friction and thus prevent the generation of heat and the formation of an increase. As oils represent a very significant economic cost with this technology. Our aim is to replace oils with cutting fluid and thus reduce the operating costs of this technology, while maintaining the required roghness of the treated surfaces.

\subsection{Statistical methods use at broaching}

In the following chapter we will present a number of selected statistical methods which we will apply in the process of the evaluation of specific technology - broaching of internal contoured surfaces.

\section{Six Sigma Method}

It is a method use for the improvement of the processes and quality of a company formerly developed by Motorola. This approach to improvement was well-known in the 1980s. Six Sigma utilizes statistical methods and its goal is to minimalize process losses.

The aim of Sigma Six method presumes that per million pieces produced there may be a maximum of 3.4 deficiencies. Six Sigma method tries to minimalize the process variability and seeks the factors which are responsible for it and which are subsequently to be handled. Lean is exclusively interested in the process waste, Six Sigma focuses of their variability. Overall, Six Sigma offers two approaches - DMAIC and DFSS. DMAIC is used to improve the already-existing processes and DFSS is used in the designing of new processes [Lean 2021].

\section{DMAIC Method}

In order to successfully implement the changes or the management of the project aimed at the improvement this method is defined by 5 phases: Define, Measure, Analyse, Improve, Control. Continuous process improvement is included in the KAIZEN methodology. 
DMAIC method can be used to solve various problems with the aim of the improvement of the processes. DMAIC method can be used to solve various problems with the aim of the improvement of the processes. The method DMAIC we use as a SIPOC form in which the task of the process of broaching of internal contoured surface is being solved. SIPOC is form for Six Sigma, where the terms mean: $\mathrm{S}$ - Supplier, I - Input, P Process, $\mathrm{O}$ - Output, $\mathrm{C}-$ Customer.

A powerful tool for statistical evaluation [Terek 2004] of processes (production, experimental, research) are various software platforms, which offer not only basic statistical evaluation but various other functions, extended is e.g. software MiniTAB [Peterka 2020a, Vozar 2019].

\section{RESULTS AND DISCUSSION}

This chapter describes the experiments, experimental conditions, conditions and methods for obtaining experimental data. It also quantifies the results achieved and discusses them qualitatively.

\subsection{Experimetns of a broaching of internal shaped surface}

Experimental tests were performed on the workpiece, where the surface roughness is defined due to further assembly. In the experiment itself, the influence of the broaching process under the conditions of different cutting fluids in relation to the resulting surface roughness was evaluated. In obtaining information and collecting data from the real production process of broaching the inner contoured surfaces, it was found that cutting oil is used as the process fluid. The results of the experiment show that with the current rapid development of technologies in the field of metal machining and new knowledge in the field tribology, there are opportunities to research existing production processes, analyze them, find new solutions and introduce changes leading to optimalization and cost reduction.

Experiments of broaching of internal contoured surfaces under different conditions of process fluids and evaluation of roughness of machined surface. The main role of the process fluid in the machining process is to cool the friction node at the cutting point in order to extend the life of the cutting tool [Jurina 2020]. Other capabilities of the process fluid are to preserve the treated surface and prevent its oxidation. The process fluid also helps to reduce the thermal load on the machined surface during broaching. In solving the goal of the experiments, the main input conditions of the investigated technology of broaching the holes of the inner shaped surfacemachine, tool, process fluid and workpiece - were defined at the beginning. Description of the workpiece - it is the outer ring of the freewheel, which is cast into the stator according to Fig. 1. The freewheel material used is C45. C45 or 1.0503 is Non-alloy quality carbon steel. The chemical composition [\%] of this steel is: $\mathrm{C} 0.43-0.5$, Si $\max 0.4, \mathrm{Mn} 0.5-0.8, \mathrm{Ni} \max 0.4, \mathrm{P}$ $\max 0.045, \mathrm{~S} \max 0.045, \mathrm{Cr} \max 0.4$, Mo $\max 0.1$. The mechanical properties of steel grade C45: Hardness Brinell hardness (HBW): (+S) 255, Tensile $R_{m} 898$ [MPa], Elongation $A$ [\%] 13. The prescribed surface roughness after broaching is $R z_{25}$.

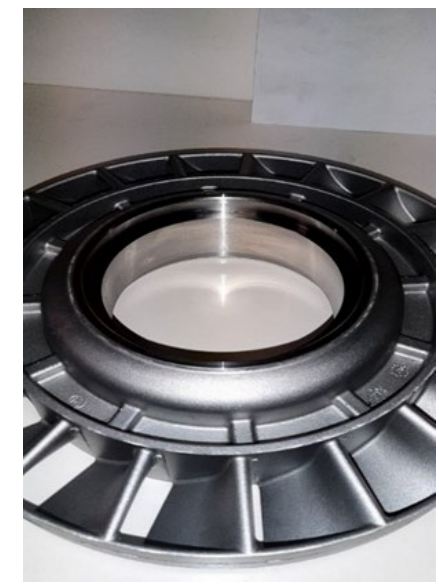

Figure 1. Workpiece before broaching

The test was carried out at an automated workplace with a hydraulic broaching machine 7B66, manufactured by Minsk Machine Company. Roghness measurements were performed on a Mahr MarSurf XCR20 measuring device, shows in Tab. 1.

Table 1. Experimental conditions for broaching tests

\begin{tabular}{|c|} 
Name \\
Machine 7B66 \\
\hline Length of the broaching tool $1100[\mathrm{~mm}]$ \\
\hline Cutting speed $2.5\left[\mathrm{~mm} \mathrm{~min}^{-1}\right]$ \\
\hline Workpiece material C45 \\
\hline Roughness measuring device Mahr MrSurf \\
\hline Number of grooves 24
\end{tabular}

The measurement of surface roughness after broaching is shown in Fig. 2.

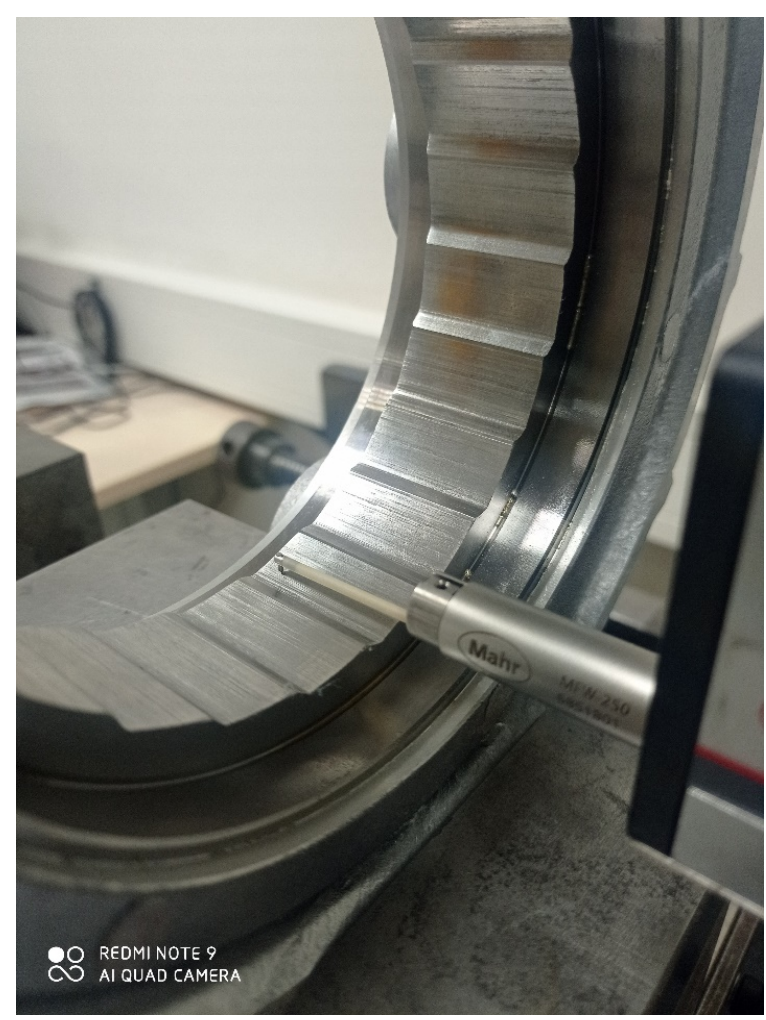

Figure 2. Surface roiughness measurement

\section{Experiment No. 1}

Cutting oil ECOCUT 715 was used as the process fluid in experiment No. 1, which was used in broaching workplaces in 
series production. ECOCUT 715: Chlorine free sulphur containing low viscosity, highly active cutting oil for difficult machining. Recommended for broaching and gun drilling application [Fuchs 2019].

\section{Evaluation of experiment No.1}

The implementation of the broaching test of the inner shaped surface brought positive results and the roughness values were achieved, is shown in Fig. 3.

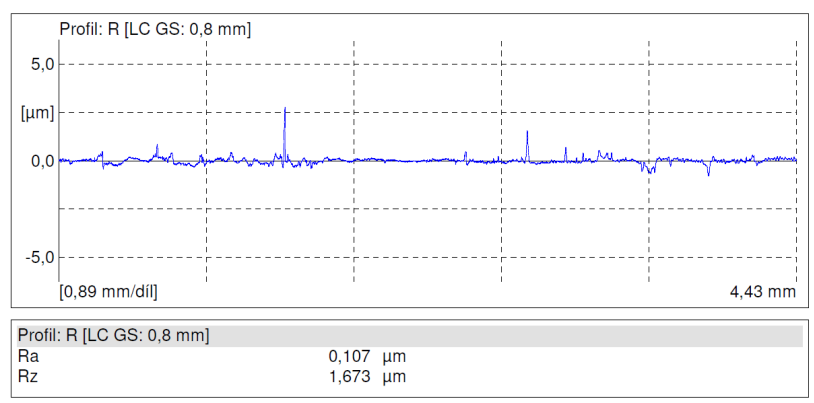

Figure 3. Roughness profile in experiment No. 1

\section{Experiment No. 2}

The test involved changing the cutting oil from resevoir to an emulsion - cutting fluid Blaser BLASOCUT 4000 Strong. The first test of broaching of the inner shaped surface under emulsion fluid conditions was performed at a concentration $5 \%$, as is commonly used in other metal chip processing processes (e.g. turning). Blasocut Blasocut - High performance water miscible mineral oil-based cutting fluids for all machining operations for extended tool life and good surface finish [Blaser 2017].

\section{Evaluation of experiment No. 2}

The broaching test of the inner shaped surface under emulsion liquid conditions was performed at a concentration of $5 \%$. The broaching tool quickly wore out under these cutting conditions and the broaching tool was almost damaged. This was then used for grinding on a Sharpmaster 2200 machine from the manufacturer KARL KLINK Company.

\section{Experiment No. 3}

Based on the knowledge gained from experiment No. 2, its analysis, evaluation and improvement of processes [Kosturiak 2010], experiment No.3 was prepared. The process of broaching the inner shaped surface was under conditions Blaser BLASOCUT 4000 Strong emulsion liquid. The concentration of the emulsion liquid changed to $15 \%$.

\section{Evaluation of experiment No. 3}

The broaching test of the inner shaped surface under emulsion liquid conditions was performed at a concentration of $15 \%$. The result of the broaching test at this concentration gave positive results and the roughness values are shown in Fig. 4.

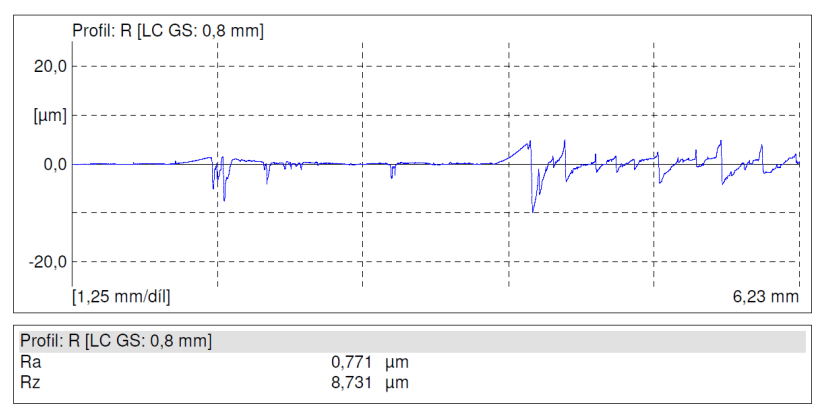

Figure 4. Roughness profile in experiment No. 3

\subsection{Experimental results and discussion to the roughness}

The results of the experiments for individual roughness measurements are summarized in Tab. 2 . In the table we see a comparison of the achieved average values of the machined surface roughness for the parameter $\mathrm{Ra}$ mean arithmetic deviation and for the roughness parameter $R z$ the maximum height of surface roughness.

Tab. 3 shows the achieved roughness parameters for different types of cutting media - oil ACOCUT 715 and BLASOCT 4000 emulsion for $5 \%$ and $15 \%$ concentration, and the Requested Roughness from the drawing - Fig. 5.

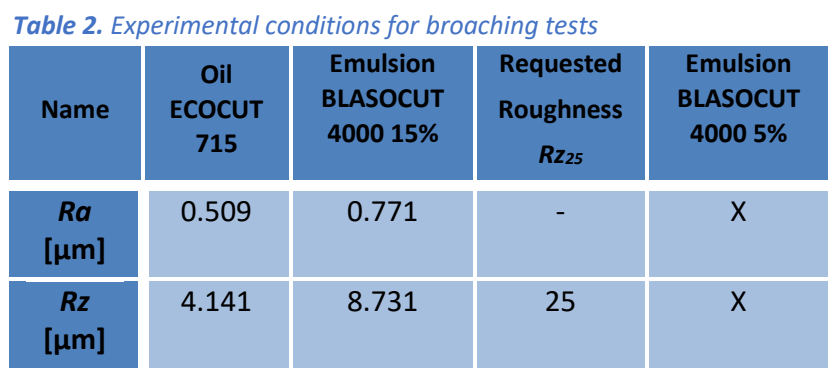

$R a$ - arithmetical mean roughness value, $R z$ - maximum roughness height (depth), $X$-damaged tool

From the above results, the following findings can be stated which are based on the performed experiments and measured values of roughness parameters:

1. The use of a low concentration emulsion - BLASOCUT 4000 $5 \%$ seems inappropriate due to the fact that the cutting tool - the broaching tool - quickly worn out and quickly lost its cutting ability.

2. It is more advantageous to use emulsions with a higher concentration, e.g. BLASOCUT $400015 \%$. The tool - the broaching tool did not wear out so quickly and was not damaged. Better groove roughness values were achieved than for the cutting medium - BLASOCUT $40005 \%$.

3. ECOCUT 715 oil as a cutting medium achieved very good results in terms of roughness parameters $(R a, R z)$ of machined grooves. Compared to BLASOCUT $400015 \%$ emulsion, better roughness values were achieved. The parameter $R a$ was $0.262 \mu \mathrm{m}$ better resp. $34 \%$ better. The parameter $R z$ was $4.590 \mu \mathrm{m}$ better resp. $53 \%$ better.

4. The prescribed (requested) roughness value of the parameter of the maximum height of the profile of the inner surfaces of the grooves according to the drawing documentation was Rz25 Fig. 5. When using both cutting media, i. ECOCUT 715 oil and BLASOCUT $400015 \%$ emulsion, satisfactory roughness from the point of view of the drawing documentation was achieved.

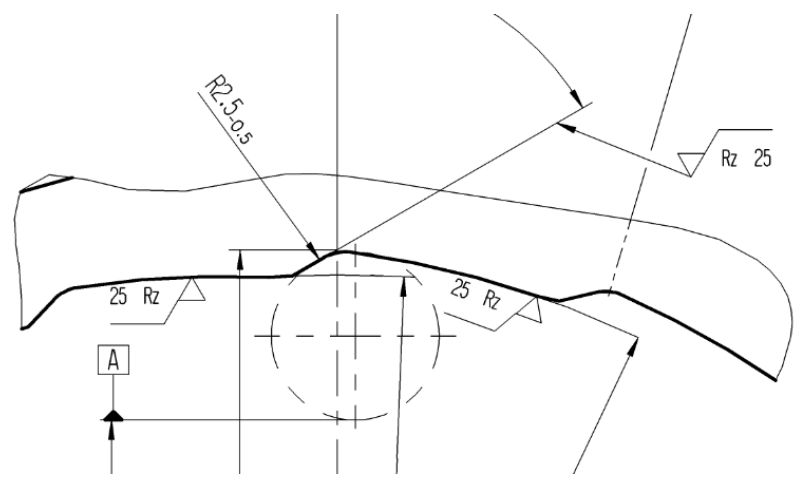

Figure 5. Detail of the inner groove with roughness marking $R z_{25}$ 
5. ECOCUT 715 oil achieved better $R z$ values compared to the prescribed (requested) $R z 25$ value by $20.859 \mu \mathrm{m}$ resp. roughness was 6,036 times better.

6. The emulsion BLASOCUT 4000 15\% ECOCUT 715 achieved better $R z$ values compared to the prescribed (requested) $R z 25$ value of $16.269 \mu \mathrm{m}$ resp. the roughness was 2.863 times better.

\subsection{Monitoring of the machine capability}

Describes an area of implementation of statistical control of the process and monitoring of the machine's capability. Under capability of the process we understand the evaluation of the process performance measured according to specifications. The ability is expressed by capability indicator. Terms:

- Random factor - causes a constant variance which is typical for the process as a part of the total variance (e.g. fluctuations in the quality of raw materials).

- Systematic factor - causes an irregularly occurring variance (e.g. broken tool).

- Capability of the machine / process is a ratio of tolerance and accuracy of production.

To express the evidence of monitoring of the machine/process capability, Tab. 3 includes the types of tests, methods and indicators of capability.

Table 3. Indicators of machine/process capability

\begin{tabular}{|c|c|c|}
\hline Test Type & Method & $\begin{array}{r}\text { Capability } \\
\text { Indicators }\end{array}$ \\
\hline Short-term test & Machine capability & $C_{m}, C_{m k}$ \\
\hline Short-term test & $\begin{array}{r}\text { Preliminary process } \\
\text { capability }\end{array}$ & $P_{p,}, P_{p k}$ \\
\hline Long-term test & $\begin{array}{r}\text { Continuous process } \\
\text { capability }\end{array}$ & $C_{p}, C_{p k}$ \\
\hline
\end{tabular}

Demonstration of machine and process capability is performed on critical and important features, or upon the requests of the
These are the factors that are generally regarded as causing variation in capability measurements [Nielsen 2020]:

- Machine (e.g. degree of wear and choice of tooling);

- Measurement (e.g. resolution and spread of measuring instrument);

- Operator (e.g. how experienced and careful he/she is);

- Material (e.g. variations in surface smoothness and hardness);

- Environment (e.g. variations in temperature, humidity and voltage);

- Method (e.g. type of machining operation).

These factors work randomly or systematically. In case of unsatisfactory test results these should be taken into account in the process analysis.

On the following example we will explain which approach can be used to express the effect the parameters have on other parameters in the process of broaching of internal contoured surface of the profile shape.

The description of the shaped component - it is a pump welded from two component parts, a circular pressing with the outer diameter D1 $=280 \mathrm{~mm}$, an internal opening D2 $=53 \mathrm{~mm}$, and an impeller hub which is inserted into the internal opening of the pressing. The component parts are welded. The impeller hub has a through hole designated for the broaching of the internal contoured surface of a section. The profile shape is a module 32. Used hub material JIS G4051 S48C. The test was performed at an automatic workplace with a hydraulic broaching machine 7B66. Cutting speed $3.5 \mathrm{~m} / \mathrm{min}$. Cutting oil was used ECOCUT 715 [Fuchs 2019].

As a test we can use a capability test with the assessed indicators of capability $C_{m}$ and $C_{m k}$. A specific assessed parameter of the shaped component is the diameter of the hole $D=48$ h10 $(-0,1)$. A tested dose of the measured components is 50 pcs. A graphical demonstration of the capability assessment is shown in Fig. 6 - Fig. 8.

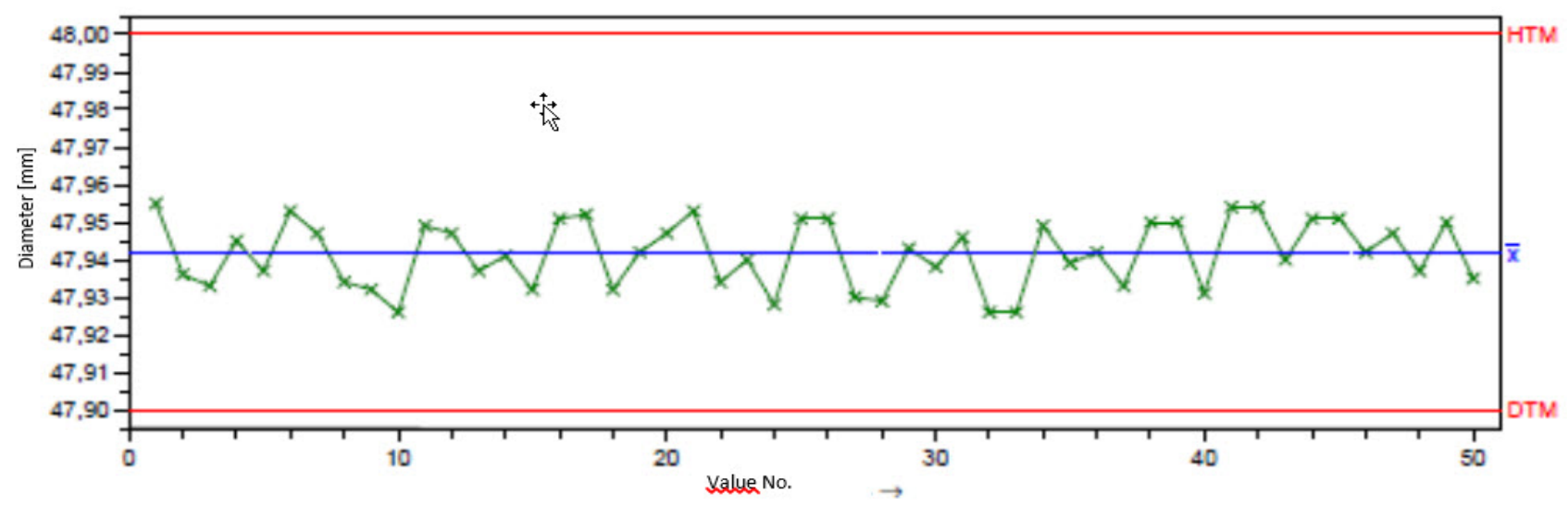

Figure 6. Measured dimensions (Diameter) for each samples (Value No.)

HTM - upper limit dimension, DTM - lower limit dimension, $\bar{X}$ - mean deviation of the dimension. 

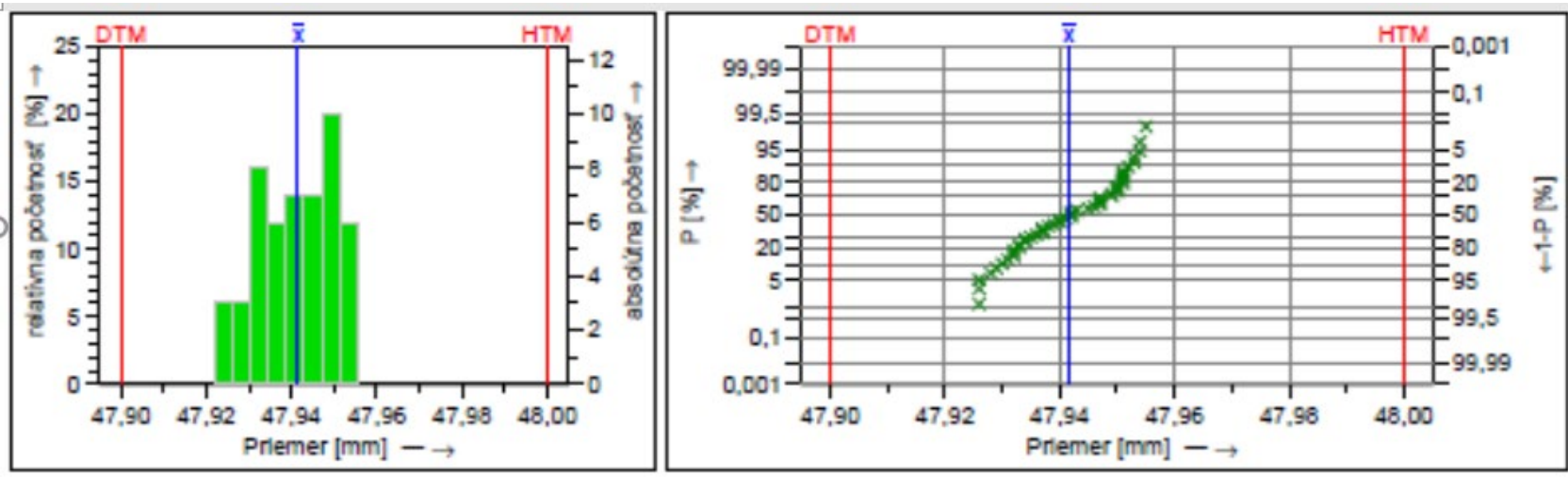

Figure 7. Assessment of capability indicators $C_{m}$ and $C_{m k}$

Relativna pocetnost $=$ Relative abundance, Absolutna pocetnost $=$ Absolute abundance, Priemer $=$ Diameter, $\mathrm{P}-$ Probability

\begin{tabular}{|c|c|c|c|c|c|}
\hline \multicolumn{2}{|r|}{ Udale $z$ wykresu } & \multicolumn{2}{|c|}{ Namerane hoónoty } & \multicolumn{2}{|c|}{ Statisticke hodnoty } \\
\hline$T_{\mathrm{m}}$ & 47,950 & & & $\bar{x}$ & 47,94156 \\
\hline DTM & 47,900 & $x_{\min }$ & 47,926 & & \\
\hline HTM & 48,000 & $x_{\operatorname{mog}}$ & 47,955 & & \\
\hline \multirow{6}{*}{\multicolumn{2}{|c|}{0,100}} & $R$ & 0.029 & & \\
\hline & & 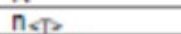 & 50 & P $\triangle T$ & - \\
\hline & & $n \times t r y$ & 0 & Pxtry & - \\
\hline & & $\mathrm{n}<\mathrm{DT}$ & 0 & PeDTY & - \\
\hline & & $n(c e l) g^{*}$ & 50 & & \\
\hline & & n(cel) ank & 50 & & \\
\hline \multicolumn{3}{|c|}{ Modelove rozdelenie } & & \multicolumn{2}{|c|}{ zladne rozdelenle } \\
\hline \multicolumn{3}{|c|}{ Typ vypoctu } & & \multicolumn{2}{|c|}{ M-WW } \\
\hline \multicolumn{2}{|r|}{ sposoollost (potenclal procesu) } & $\mathrm{C}_{\mathrm{m}}$ & 2,58 & \multicolumn{2}{|c|}{1,57} \\
\hline \multicolumn{2}{|r|}{ vyuztie sposobllostl } & $\mathrm{C}_{m k}$ & 2,01 & \multicolumn{2}{|c|}{1,57} \\
\hline \multicolumn{6}{|c|}{ Pozladavky spinene $\left(C_{m}, C_{m k}\right)$} \\
\hline
\end{tabular}

Figure 8. Assessment of capability indicators $C_{m}$ and $C_{m k}$

Notes : Udaje z vykresu = Data from the drawing, Namerane hodnoty = Measured values, Statisticke hodnoty= Statistical values, Modelove rozdelenie $=$ Model distribution, ziadne rozdelenie $=$ no distribution, Typ vypoctu $=$ Calculation type, sposobilost $($ potencial procesu) $=$ capability (process potential), vyuzitie spusobilosti = capability utilization, Poziadavky splnene $\left(C_{m}, C_{m k}\right)=$ Requiements met, $T_{m}$ - Mean value of the tolerance field, DTM - Lower value of the tolerance field, HTM - Upper value of the tolerance field, T - tolerance, $X_{\min }$ - minimum measured value, $X_{\min }$ maximum measured value, $R$ - Variance of measured values, $n$ - number of values,

The $C_{m}$ index describes machine capability; it is the number of times the spread of the machine fits into the tolerance width. The higher the value of $C_{m}$, the better the machine. Example: if $C_{m}=2.5$, the spread fits $2 \frac{1}{2}$ times into the tolerance width, while $\mathrm{Cm}=1$ means that the spread is equal to the tolerance width. If you also want to study the position of the machine's capability in relation to the tolerance limits, you use the $C_{m k}$ index, which describes the capability corrected for position. It is not much use having a high $C_{m}$ index if the machine setting is way off centre in relation to the middle of the tolerance range. A high $C_{m k}$ index means, then, that you have a good machine with a small spread in relation to the tolerance width, and also that it is well centred within that width. If $C_{m k}$ is equal to $C_{m}$, the machine is set to produce exactly in the middle of the tolerance range. A normal requirement is that $C_{m k}$ should be at least 1.67 [Nielsen 2021].

In our case, we can see, in Fig. 7, the values of the capability indicators $C_{m}$ a $C_{m k}$ are greater than the normal requirement:

$$
\begin{aligned}
& C_{m}=2.58 \geq 1.67 \\
& C_{m k}=2.01 \geq 1.67
\end{aligned}
$$

where $C_{m}$ is machine capability indicator,

$C_{m k}-$ corrected machine capability indicator.
From the above results, the following findings can be stated to evaluate the ability to stretch the inner grooves:

1. The $C_{m}$ indicator exceeded the set limit of 1.67 by 0.91 resp. 1.54 times. The $C_{m k}$ indicator exceeded the set limit of 1.67 by 0.34 resp. 1.20 times.

2. For the $C_{m}$ indicator, tha range fits 2.58 times the tolerance width.

3. Based on the $C_{m k}$ indicator, it can be stated that the broaching machine is in good condition and is well centered.

\section{CONCLUSIONS}

Based on the planned experiments and performed tests in the conditions of broaching internal contoured surfaces, it was found that on existing broaching technologies and identical tools in series production it is possible to broach workpieces after changing the cutting oil to emulsion fluid to achieve the required surface roughness quality. The results of experiments No.2 and No.3 showed the importance of the size of the concentration of the emulsion liquid on the broaching process. In the next step, it is recommended to map the range of emulsion fluids, analyze the parameters and compare them with the test and perform new tests. 
The technology of broaching of internal contoured surfaces enables us to achieve high productivity level in the production process and it is applicable in series and mass-produced production. At present it is implemented mainly in the production of automotive components.

A statistical control of the production process is already widely used in the production processes of the chip machining of metals. When addressing customer requirements, optimization of cost reduction and also when executing an actual research, the statistical methods represent a suitable tool in the solution of the goals. The use of statistical methods in the area of chip machining of metals in the technology of broaching of internal contoured surfaces enables to indicate the effect of the process of broaching on other parameters. This is fitting in addressing of requirements of the client as well as in case of actual research and experiments. Under conditions of series production, the implementation of a statistical process control represents a quality management tool. Experimental tests were performed on a part that is welded from two parts, a circular pressing and an impeller hub which is inserted into the internal opening of the pressing. In the experiment itself, the influence of the broaching process on another parameter of the welded part was evaluated. The results of the experiment show that the use of statistical methods is suitable for tests of broaching of internal contoured surfaces.

\section{ACKNOWLEDGMENTS}

This article was supported by the scientific grant agency of the slovak republic under the grant no. 1/0019/20.

\section{REFERENCES}

[Blaser 2017] BLASOCUT 4000 CF PDF. Blasser Swisslube. Date of webpage actualization: September 25, 2020. Date of citing: [13.11.2021]. Available from < https://euts.me/blasocut-4000-cf-90/>

[Bredthat 2021] Bredthauer, M. et al. Effects of Grinding wheel wear on the thermo-mechanical loads in the grinding process. MM Science Journal. July 2021, ISSN 1803-1269, ISSN 1805-0476

[DIN 2003] Deutsche Norm (German standard) DIN 8589-5. 2003. Fertigungsverfahren Spanen Teil 5 Raeumen (Manufacturing process chip removal - Part 5: Broaching). Beuth Verlag GmbH, Berlin

[Fuchs 2019] FUCHS LUBRICANTS. TECHNOLOGY. PEOPLE. Metal processing / Cutting \& Grinding ECOCUT 715. ECOCUT 715. Date of webpage actualization: 2021. Date of citing: [13.11.2021]. Available from < https://www.fuchs.com/in/en/product/product/79 796-ecocut-715/

[Jing 2016] Jing, $\mathrm{Ni}$ et al. Investigation on broaching performance and unloading mechanism of microtextured broach. The International Journal of Advanced Manufacturing Technology. January 2016, Vol.86, pp 2449-2458. Print ISSN 0268-3768, Electronic ISSN 1433-3015

[Jurina 2021] Jurina, F. et al. Device for automatic data collection on selected properties of cutting fluid: utility model application nr. 35 - 2020, Application date: 24.03.2020, Publication date of published application 24.03.2021, Vestnik UPV SR nr. 06/2021, condition:valid, registered UV nr. 9240, date of notification of registration UV: 28.07.2021, Vestnik UPV SR nr. 14/2021. Banska Bystrica: Industrial property office SR, 2021. p. 5 . https:indprop.gov.sk/WebRegistre/UzitkovyVzor/De tail/35-2020.

[Karl 2021] Karl Klink Werkzeug- und Maschinenfabrik. Date of webpage actualization: 2021. Date of citing: [10.10.2021]. Available from < https://www.karlklink.de/cn/Produkte/Raeummaschinen/>

[Kolesnyk 2020] Kolesnyk, V. et. al. Experiemntal Study of Drilling Temperature, Geometrical Errors and Thermal Expansion of Drill on Hole Accuracy When Drilling CFRP/Ti Alloy Stacks. Materials. Special Issue Machining and Manufacturing of Alloys and Steels. July 2020, Vol.13, No.14, p 3232. Available from < https://doi.org/10.3390/ma13143232>. EISSN 1996 $-1944$

[Kosturiak 2010] Kosturiak, J. et al. 2010. Kaizen. Brno: Computer Press, 2010. ISBN 978-80-251-2349-2

[Lean 2021] 60 Lean Six Sigma Consulting Company. Metodologie - Six Sigma. Date of webpage actualization 2021. Date of citing [10.10.2021]. Available from < https://lean6sigma.cz/six-sigma/>

[Lipa 2007] Lipa, Z. et al. The geometric, kinematic and dynamic machining analysis. Research papers MTF STU Trnava, 2007, page 98, ISSN 1336-1589

[Makarov 2010] Makarov, V.F. and Tyktamyshev, V.R. Numerical Modelling of High Speed Broaching Multitoothes Broaches. International Journal of Material Forming. 2010, Vol.3, No.1, pp 523-526. Print ISSN 1960-6206, Electronic ISSN 1960-6214. DOI10.1007/s12289-010-0822-0

[Makarov 2008] Makarov, V.F. et al. High speed broaching of hard machining materials. International Journal of Material Forming. April 2008, Vol.1, No.1, pp 547550. Print ISSN 1960-6206, Electronic ISSN 19606214. DOI10.1007/s12289-008-0276-9

[Milde 2021] Milde, J. et al. Influence of Part Orientation on the Surface Roughness in the Process of Fused Deposition Modeling. In: Key Engineering Materials. August 2021, Vol.896, pp 29-37. Internatioal Conference on Building Materials and Construction (ICBMC 2021), Nanotechnology and Nanomaterials in Energy (ICNNE 2021), Energy Engineering and Smart Mat. (ICEESM 2021). ISSN: 1662-9795, Linking ISSN (ISSN-L): 1013-9826

[Navukkarasan 2020] Navukkarasan, A. et. al. Experimental investigation of dry and cryogenic broaching of AISI 4340 steel. Materials and Manufacturing Processes. June 2020, Vol.35, No.14, pp 1584-1597. Print ISSN: 1042-6914, Online ISSN: 1532-2475 DOI10.1080/10426914.2020.1779940

[Nielsen 2021] Nielsen, M. Statstical process control (SPC). Glossary. Date of citing [13.11.2021]. Available from <https://statisticalprocesscontrol.info/glossary.html

[Ozelkan 2011] Ozelkan, EC. et al. Identifying parameters of a broaching design using non-linear optimisation. Inter. Journal of Modelling Identification and Control. 2011, Vol.12, No.3, pp 244-252. ISSN online: 1746-6180, ISSN print: 1746-6172. DOI10.1504/IJMIC.2011.039702.

[Peterka 2020a] Peterka, J. et al. Using multi-criteria analysis to evaluate the impact of drag-finishing technological parameters on the carbide tool radius. In: Materials Today: Proceedings. 2020, Vol.22, Part2. pp 205211. ISSN 2214-7853

[Peterka 2020b] Peterka, J. et al. Design and Manufacturing of Cutting Tools for milling. MM Science Journal. 
March 2020, pp 3818-3821. ISSN 1803-1269, ISSN 1805-0476. DOI 10.17973/MMSJ.2020_03_2019129

[Petkova 2012] Petkova et al. Tribotechnika v teorii a praxi. (Tribotechnics in theory and practice). Kosice: Vienala, 2012. ISBN 978-80-8126-057-5

[Sentyakov 2020] Senytyakov, K. et. al. Modeling of Boring Mandrel Working Process with Vibration Damper. Materials. April 2020, Vol.13, No.8, p 1931. Available < http://doi.org/10.3390/ma13081931 > EISSN 1996 - 1944

[Terek 2004] Terek, M. and Hrncarova, L. Statisticke riadenie kvality. (Statistical quality management). lura Edition, 2004. ISBN 80-89047-97-1

[Vasilko 2007] Vasilko, K. Analyticka teoria trieskoveho obrabania. (Analytical theory of chip machining). Presov: Vasilko. 2007. ISBN 978-80-8073-759-7

[Vasilko 2012] Vasilko, K. Analyticka teoria trieskoveho obrabania. (Analytical theory of chip machining). Presov: TU Kosice, 2012. ISBN 9788055309200

[Vopat 2013] Vopat, T. et. al. The Wear Measurement Process of Ball Nose end Mill in the Copy Milling Operations. In: $24^{\text {th }}$ DAAAM International Symposium on Intelligent Manufacturing and Automation. October 2013, Vol.69, pp 1038-1047. ISSN 1877-7058

[Vozar 2019] Vozar, M. et al. Multi-criteria analysis of drag finishing the cutting edges of solid carbide mills. In Manufacturing Technology - Pilsen 2019 [el. sour.] : 8th International Conference , 5. - 6. 2. 2019, Pilsen.
1. vyd. Pilsen : University of West Bohemia in Pilsen, 2019, p. 140-149. ISBN 978-80-261-0829-0

[Wiemers 2021] Wiemers KG., Raeumen (Broaching). Date of webpage actualization: 2016. Date of citing: [10.10.2021]. Available from < wiemers.de >

[Xu 2011] Xu, M. et al. Research on the Broaching-load Testing System of Hydraulic Broaching Machine. Advanced Materials Research. Trans Tech Publications LtD, Switzerland. September 2011, Vol.328-330, pp 1709-1712. Available from < DOI10.4028/www. scientific.net/AMR.328-330.1709. ISSN 1662-8985

\section{CONTACTS:}

Ing. Jozef Martinovic, MEng., Slovak University of Technology in Bratislava, Faculty of Materials Science and Technology in Trnava, Institute of Production Technologies, Jana Bottu 25, Trnava, 91724, Slovakia, +421905203187, jozef.martinovic@stuba.sk

Prof. Dr. Ing. Jozef Peterka, Slovak University of Technology in Bratislava, Faculty of Materials Science and Technology in Trnava, Institute of Production Technologies, Jana Bottu 25, Trnava, 91724, Slovakia, +421905930245,

jozef.peterka@stuba.sk 